\title{
تعرض المراهقات لاصفمات المتفصمة للمرأة عبر مواقع التواصل الاجتماعى وعلاقتة بالتثقيف الأسرى لديهن
}

\author{
أ.م.د// دعاء فكرى عبد الله \\ أ. أد/اعتماد خلف معبد \\ استاذ الصحافة المساعد كلية التربية \\ استاذ الاعلام بقسم الاعلام وثقافة الاطفال كلية \\ النوعية- جامعة المنوفية \\ الدراسات العليا للطفولة- جامعة عين شمس \\ منى فوزى شفيق ابو شنب \\ مدرس مساعد كلية التربية النوعية- جامعة المنوفية
}

ملخص الاراسة باللغة العربية:

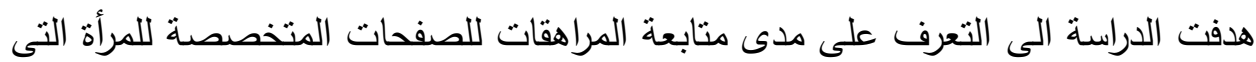

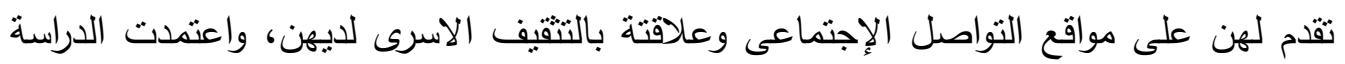

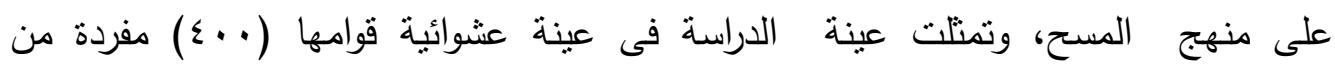

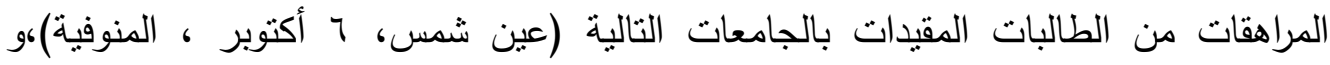

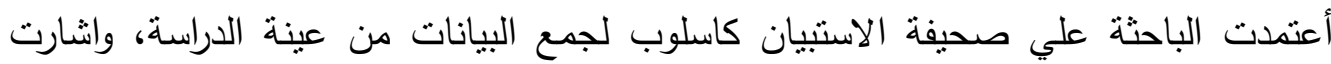

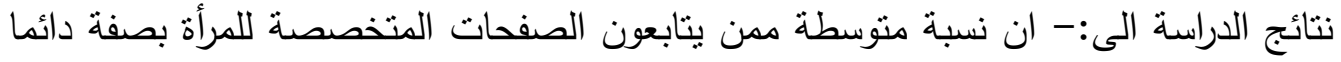

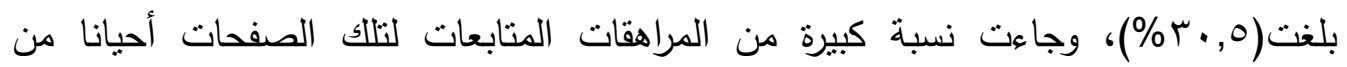

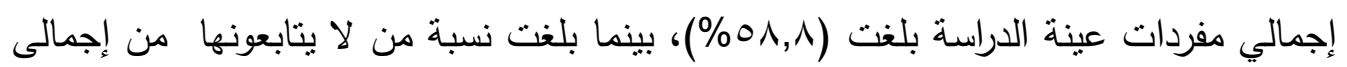
مفردات عينة المراهقات (^, •(1\%)،- و إن ان نسبة من يرون أن الصفحات المتخصصة للمرأة

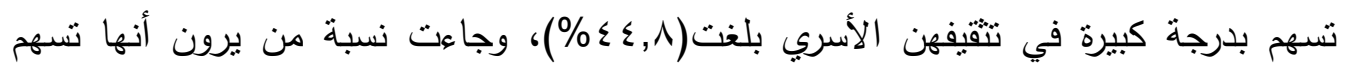

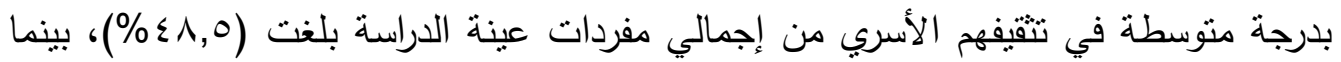

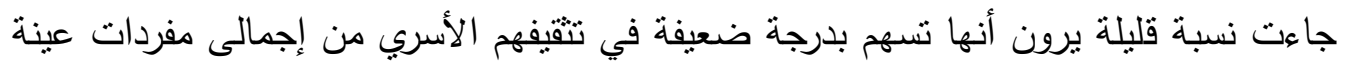

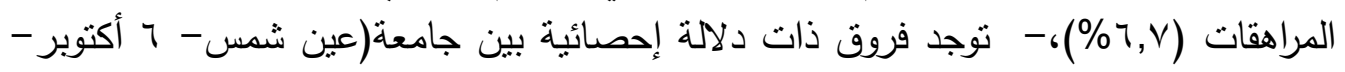

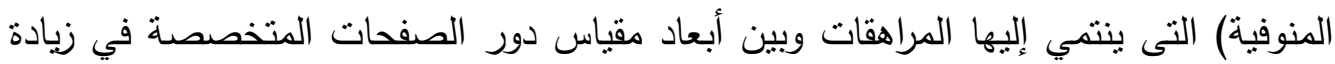

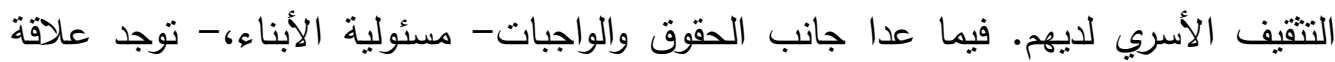

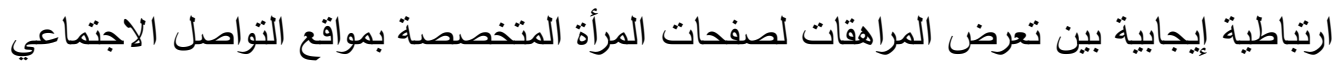

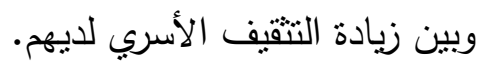

Key Words: الكلمات المفتاحية زيادة

Specialized pages for women الصفحات المتخصصة للمرأة

Social networking مواقع التواصل الاجتماعي

Family education التنقيف الأسري لتواتي 


\section{Adolescent girls were exposed to specialized pages for women through social networking sites in family education for them}

\section{Research Abstract :}

- The study aimed to identify the extent of adolescent girls' followup of the specialized pages of women presented on social media and its relationship to family education for them, and the study relied on the survey method, and the study sample consisted of $(\varepsilon \cdots)$ single adolescent girls from female students enrolled in the following universities (Ain Shams, 7 October, Menoufia). The researcher adopted the questionnaire newspaper as a method for collecting data from the study sample, and the results of the study indicated: - An average percentage of women always following specialized pages of $(r \cdot .0 \%)$, and a large percentage of adolescent girls followed these pages sometimes out of the total The vocabulary of the study sample amounted to $(0 \wedge . \wedge \%)$, while the percentage of those who did not follow it out of the total vocabulary of the adolescent sample was $(1 \cdot . \wedge \%)$. The percentage of those who believed that the specialized pages for women contribute significantly to their family education reached ( $\leqslant \leqslant . \wedge \%)$. The percentage of those who think that it contributes to a moderate degree in their family education came from the total vocabulary of the study sample amounted to $(\leqslant \wedge .0 \%)$, while a small percentage who believed that it contributed to a weak degree in their family education came from the total vocabulary of the adolescent sample ( $\urcorner. \vee \%)$. There are statistically significant differences between Ain Shams University - 7 th of October - Menoufia) to which adolescent girls belong and the dimensions of the scale of the role of specialized pages in increasing their family education. With the exception of the rights and duties aspect - the responsibility of children there is a positive correlation between adolescent girls' exposure to women's pages specialized in social media sites and their increased family education. 


\section{مقدمة:}

تقضي الفتبات في سن المراهقة قدر كبير من الوقت والجها في استخدام الصفحات

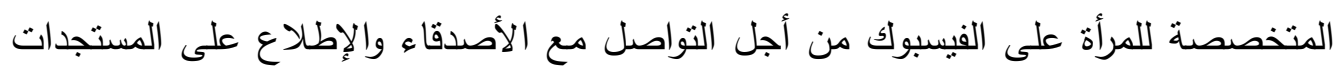

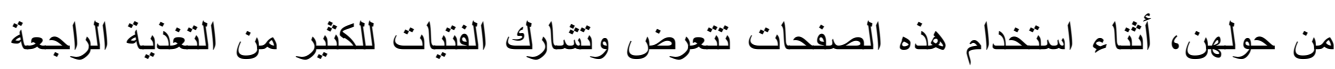
والردود والمشاركة التي تقدم الكثير من المعلومات والمعارف في مجالات مختلفة من بينها

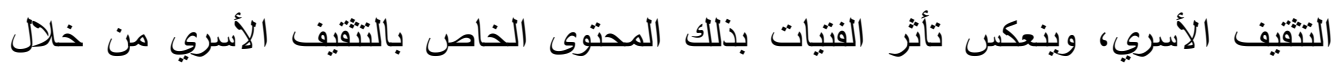

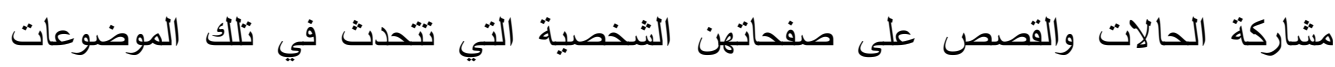

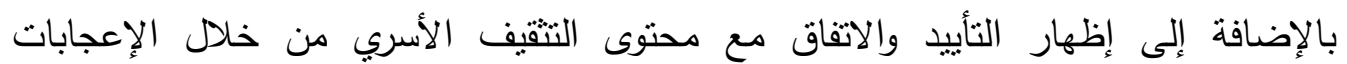
والمشاركات والإستجابات المؤيدة.

وتقدم مواقع التواصل الإجتماعي فرصة هائلة لتحسين التثقيف الأسري للمراهقات، من

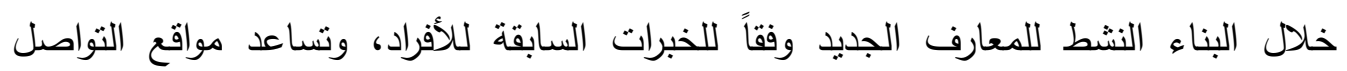
الإجتماعي على تحسين وعي والثقافة الأسرية للمراهقات عن طريق مساعدتهن على تجميع

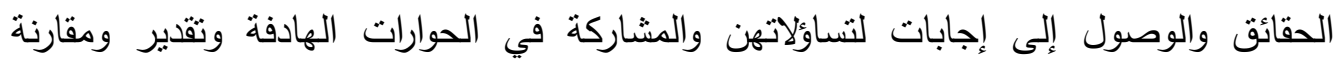

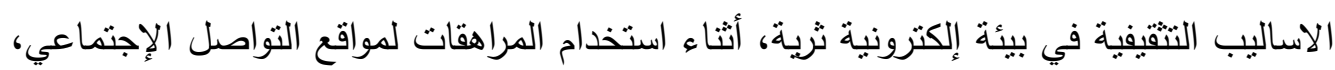

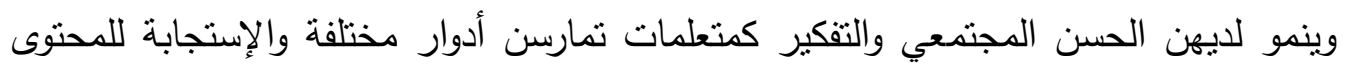

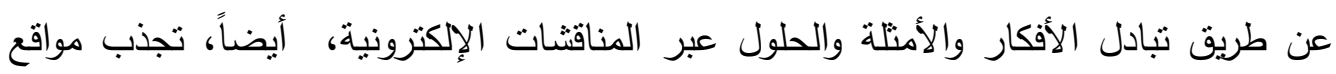
التواصل الإجتماعي المراهقات عن طريق التتوع الثقافي والإجتماعي. فمواقع التواصل الاجتماعى من اهم الوسائل للتتمية الثقافية فى مختلف مجالات الحياة،

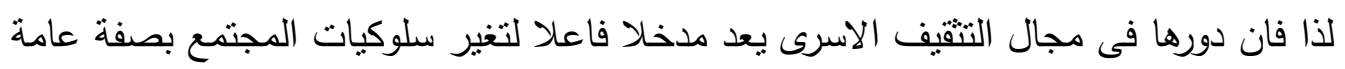
والمراهقات بصفة خاصة نحو عادات تثقيفية اسرية سليمة.

مشكلة الاراسة:

تمثل الصفحات المتخصصة أحد المزايا الهامة التي تقدمها مواقع التواصل الإجتماعي،

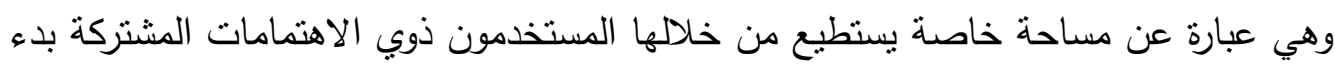

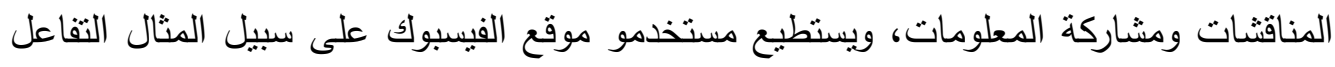

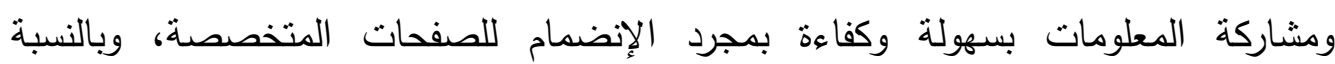

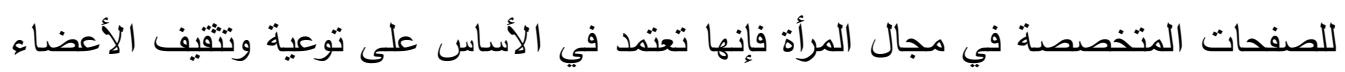

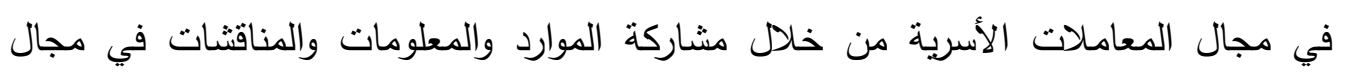
الوعي الأسري. 


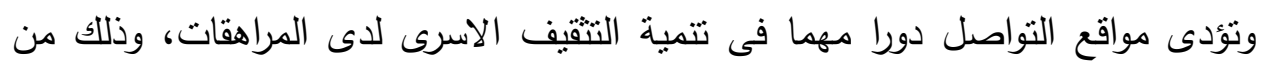

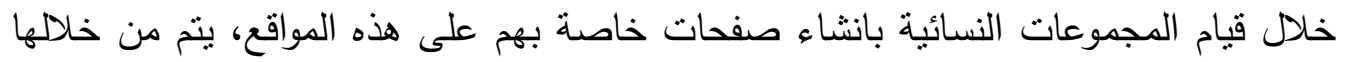

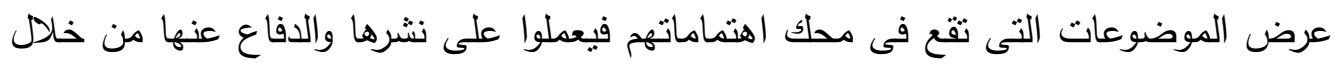

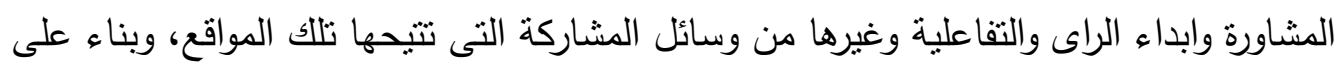

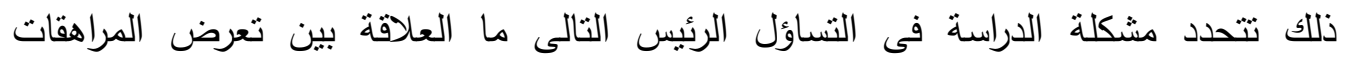

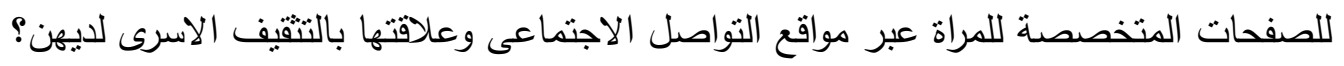

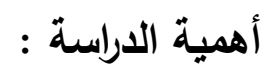

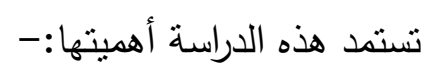
- أهمية مواقع التواصل الاجتماعى فى عصرنا الحالى، وما تتيحة من تفاعلية فيما يتعلق بالتثقيف الاسرى.

- تبصير المجتمع بصفة عامة والمراهقات بصفة خاصة باهمية التثقف الاسرى لديهن باعنبارهن امهات المستقبل.

- ت تستمد الدراسة اهميتها من اهئة اهية عينة الدراسة والتى يمثلها شريحة المراهقات ودورها المؤثز

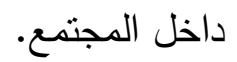
- قلة الدراسات العربية فى حدود علم الباحثة والتى تتاولت دور مواقع التواصل فى التثقيف

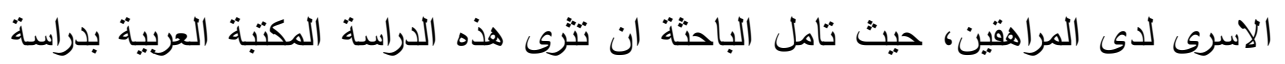
حديثة حول هذا الموضوع.

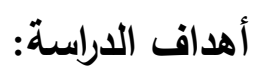
- التعرف على مدى متابعة المراهقات للصفحات المتخصصة للمرأة التى تقدم على مواقع

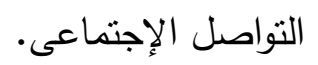
- - تحديد مدى ثقة المراهقات فيما تقدمه الصفحات المتخصصة للمراة علي مواقع التواصل الاجتماعى .

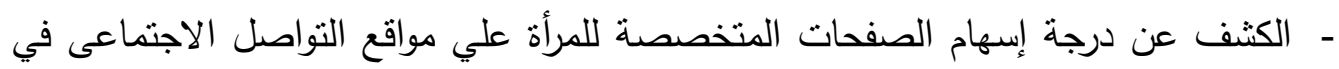
التثقيف الأسرى للمراهقات عينة الدراسة. - رصد أنثكال إسهام الصفحات المتخصصة للمراة علي مواقع التواصل الاجتماعى في التثقيف الأسرى للمراهقات عينة الدراسة.

فروض الاراسة الفرض الأول: توجد فروق ذات دلالة إحصائية بين جامعة(عين شمس - 7 أكتوبر - المنوفية)

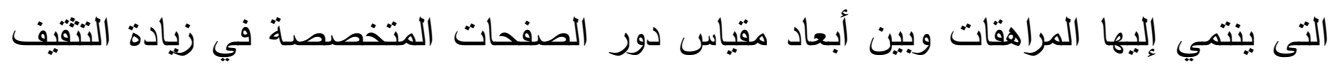
الأسري لديهم الفرض الثاني: توجد علاقة ارتباطية إيجابية بين تعرض المراهقات لصفحات المرأة

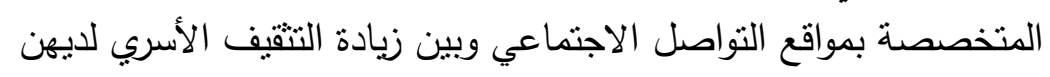




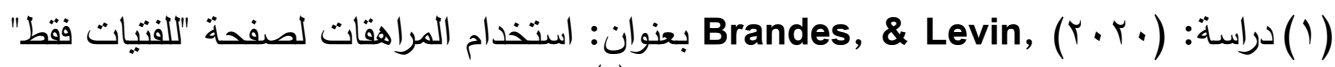
على الفيسبوك وتأثنرها على ثقافتهن الأسرية :(') هدفت الدراسة إلى فحص استخدام الفتيات

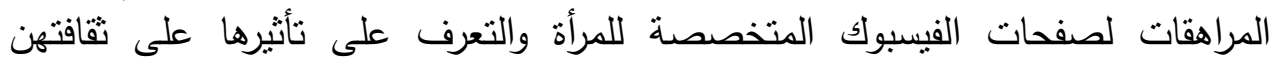
الأسرية، وتم التوصل من خلا التحليلات إلى النتائج التالية: أظهرت الإستجابات أن

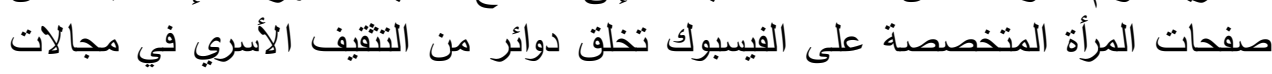
العلاقات الأسرية وديناميكيات التعامل الأسري والتوقعات المستقبلية للفتيات نحو الأسرة، توصلت الدراسة إلى أن صفحات المرأة المتخصصة تمد الفتيات بعناصر المعردات المعرفة والغرس والتوجيه فيما يتعلق ببناء ثقافتهن الأسرية، - أظهر تحليل المنشورات على صفحة "للفتيات فقط" أنها تتسم بالقوة والسيطرة المعرفية وبناء الوعي بديناميكية الأسرة وأنماط لتئاء التفاعل الأسري.

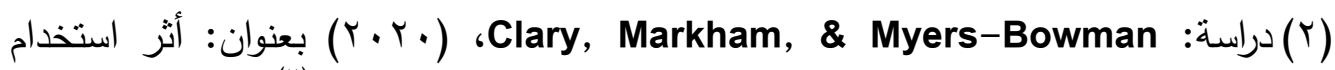
صفحات مواقع التواصل الإجتماعي على التثقيف الأسري للمراهقات:(r) هدفت الدراسة إلى على التعرف على أثث استخدام صفحات مواقع التواصل الإجتماعي على التثقيف الأسري للمراهقات في ضوء سلوكهن بتلك الصفحات، وتم التوصل من خلال التحليلات إلى النتائج التالية:- أظهر تحليل سلوكيات مشاركة الفتيات بصفحات المرأة المتخصصة فئل وجود نمطين من سلوك المشاركة: (1) تكرار محتوى التقيف الأسري على الصفحات في صورة إعادة مشاركة، ب) تسجيل الإعجاب والردود الإيجابية على محتوى التقيف الأسري المنشور بالصفحات،- خلصت الدراسة إلى وجود حجم تأثير مرتفع لإستخدام الفتيات في سن المراهقة لصفحات التواصل الإجتماعي المتخصصة في أمور المرأة وارتفاع مستويات

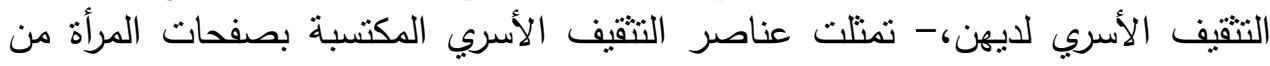

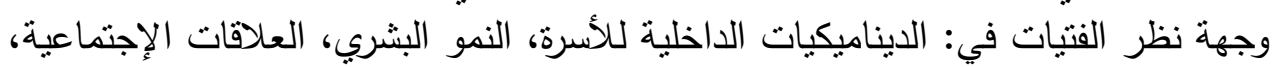
إدارة الموارد الأسرية، التربية الوالدية، وقينة الطيات وقانين الأسرة.

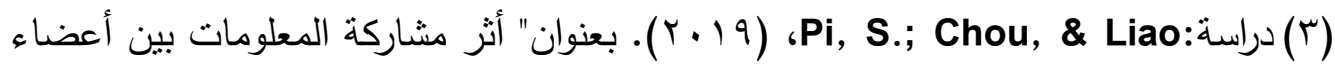

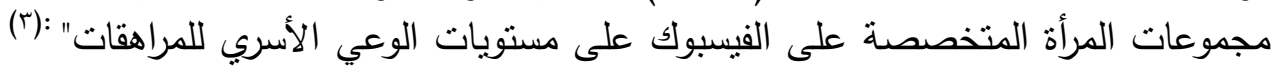

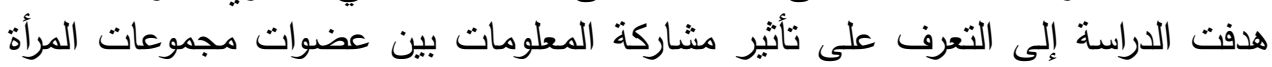
المتخصصة على موقع التواصل الإجتماعي فيسبوك على نمو الوعي الأسري للفتيات في

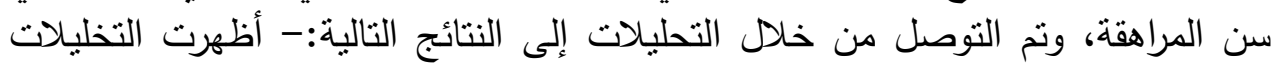

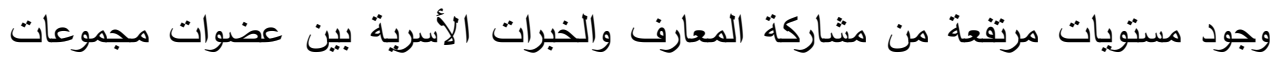
المرأة المتخصصة،-- تم التوصل إلى وجود علاقة موجبة ذات دلالة إحصائية بين مستويات مشاركة المعارف والخبرات على صفحات المرأة المتخصصة وارتفاع مستويات الوعي الأسري للمراهقات، مع وجود متغير ساعات الاستخدام كمتغير وسيطي لتلك العلاقة. 


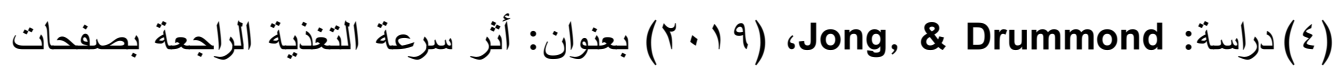

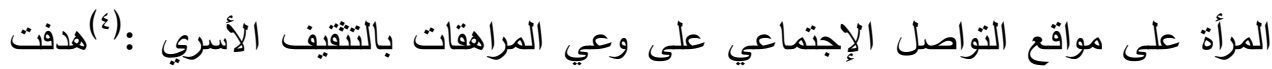

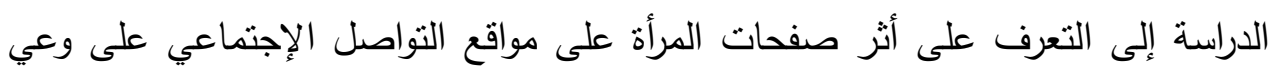

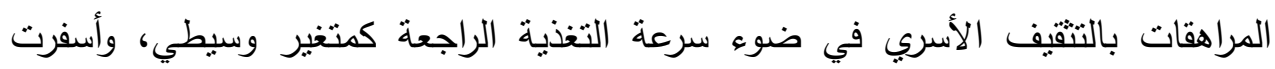

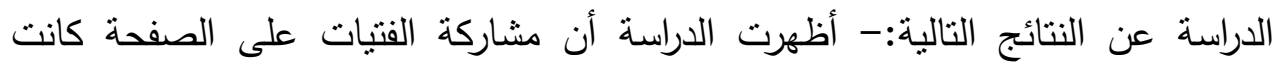

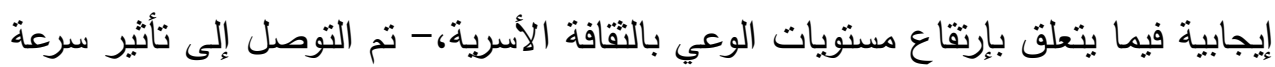

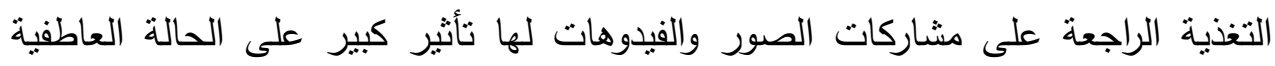

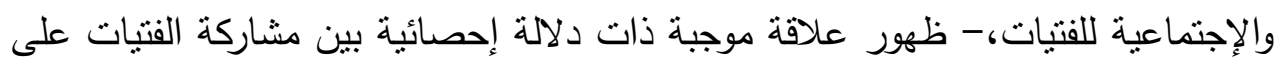

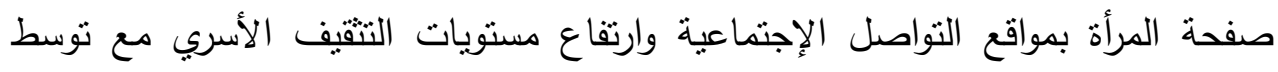
سرعة التغذية الراجعة على المشاركات لهذه العلاقة.

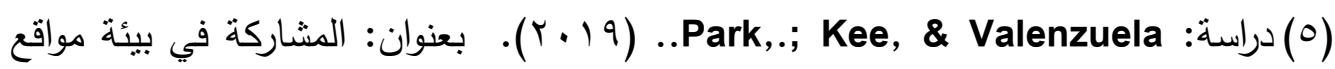
التواصل الإجتماعي: صفحات المرأة على الفيسبوك والإستخدامات والإثشباعات ونتائج

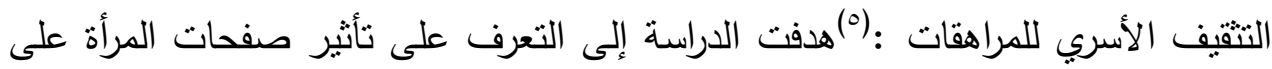
الفيسبوك على تحقيق الإثباعات والتثقيف الأسري للفتيات في سن المراهقة، ونم التوصل التهل

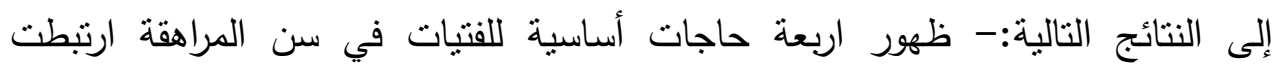

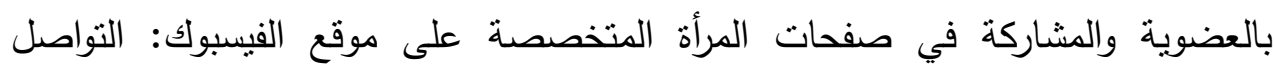

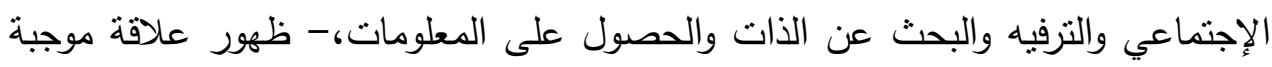

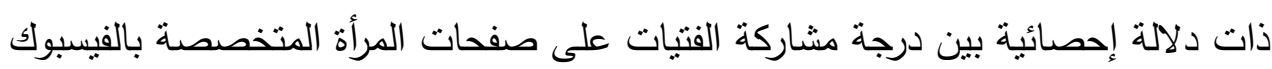

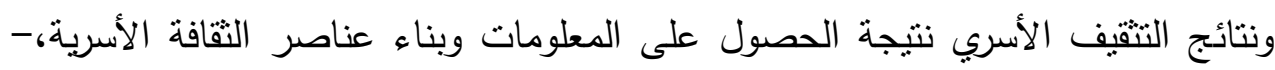
تأثز العلاقة السابقة ببعض المتغيرات الديموغرافية مثل النوع والموقع السكني والعمر . (†) دراسة: Sangeetha, N., \&Vanitha, J. J (Y.19) بعنوان: أثز صفحات مواقع

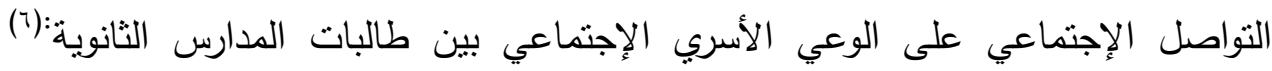

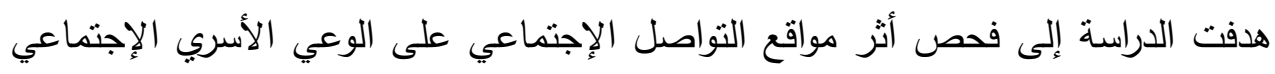

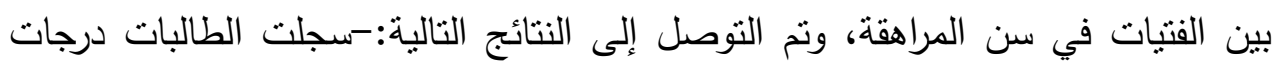

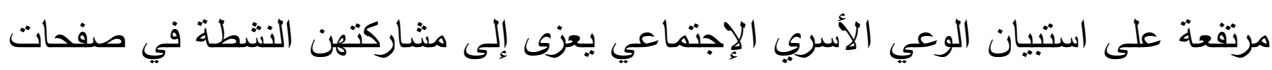

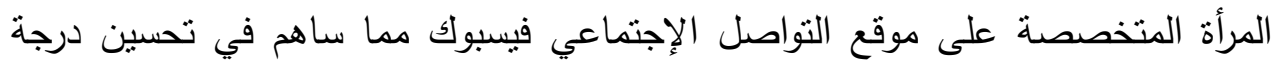

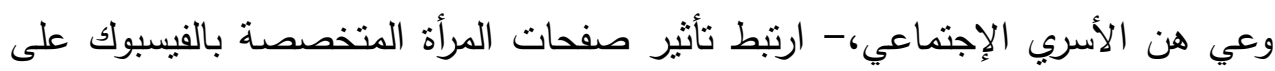
الوعي الاسري الإجتماعي للطالبات بنوع الددرسة (الخاص والعام) والسن (الفتيات الأكبر مقابل الأصغر سناً). 

المقصود بالصفحات المتخصصة عبر مواقع التواصل الاجتماعى:

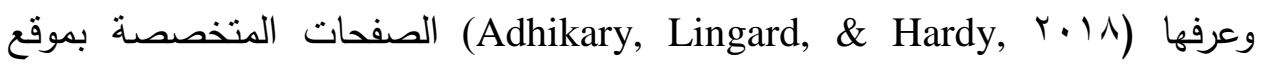
التواصل الإجتماعي بأنها "المجتمعات والمجتمعات الفرعية المتخصصة التي ينشأها

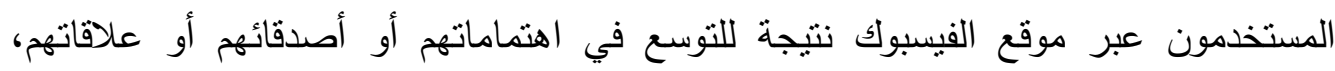

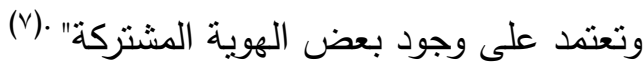

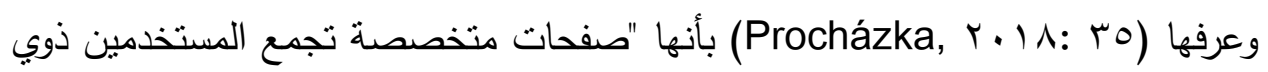

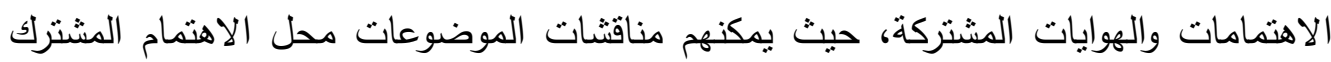

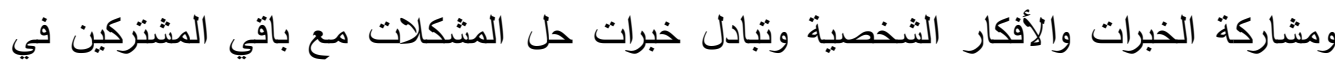

(^). الصفحة

خصائص وتصنيف واهميته الصفحات المتخصصة:

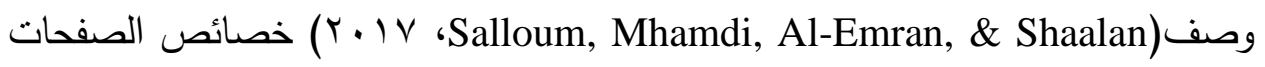

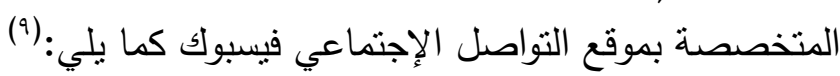
1- الإعتماد على اثتراك مجموعات كبيرة من المستخدمين بدلاً من تقديم محتوى خاضع لإصع

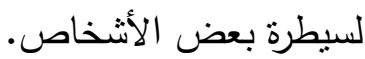

r- مشاركة المحتوى من مصادر مختلفة أهمها المحتوى المبتكر من جانب الأعضاء. r- ربط المستخدمين ذوي الاهتمامات المشتركة معاً.

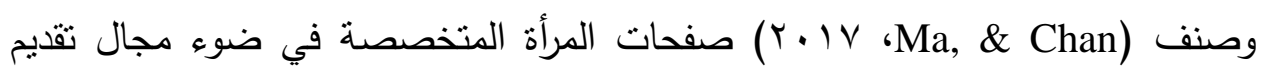

الوعي الأسري إلى:(·) (1) ( ) صفحات المرأة ذات المحتوى العام: نغطي العديد من مجالات المحتوى المرتبط بالأسرة والمعارف الأسرية.

r) صفحات المرأة ذات المحتوى الخاص: تغطي موضوعات محددة تتعلق بالحياة الأسرية

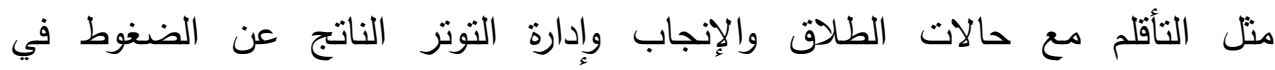
حياة الأسرة.

أثر صفحات المرأة بمواقع التواصل الإجتماعي على التثقيف الأسري:

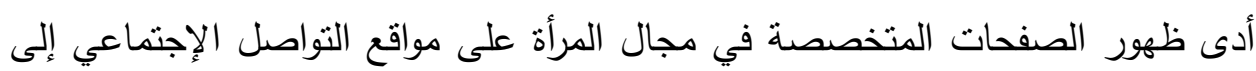
جلب أنواع مختلفة من الوعي والتثقيف في العديد من المجالات الإجتماعية وعلى رأسها الأسرة.

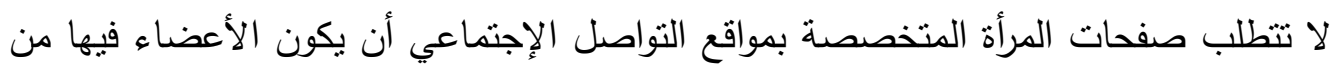

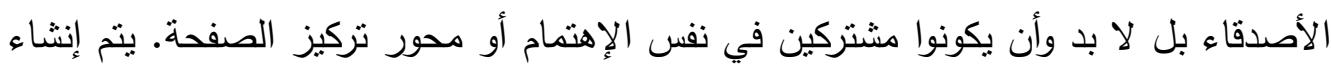


مثل هذه الصفحات عن طريق أحد مستخدمي مواقع التواصل الإجتماعي ومن ثم توجيه الدعوة

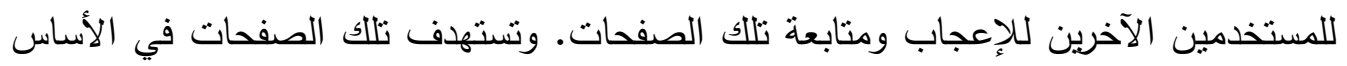

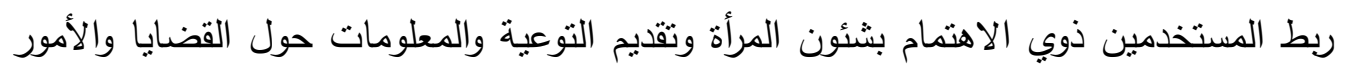

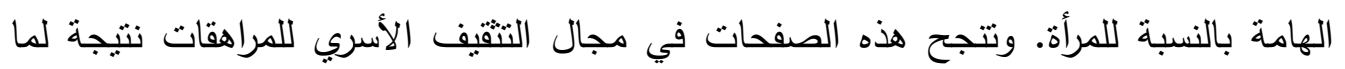

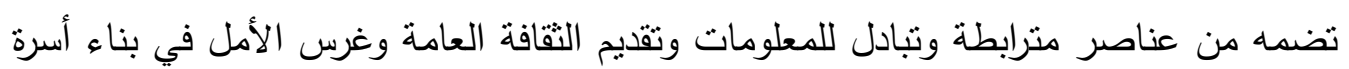

(1). صحية من فن

وتؤدي صفحات المرأة المتخصصة العديد من الوظائف في مجال التثقيف الأسري

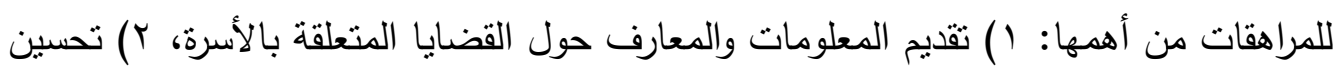

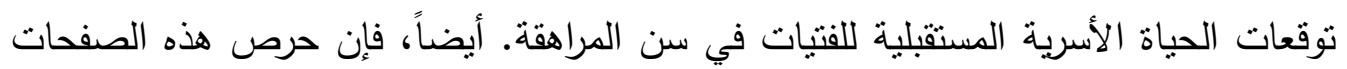
على تقديم مشاكل وحلول أسرية يعمل على تحسين وجهات نظر ومفاهيم الفتيات المراهقات

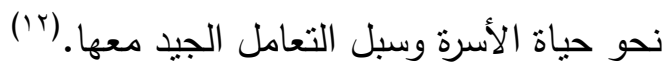

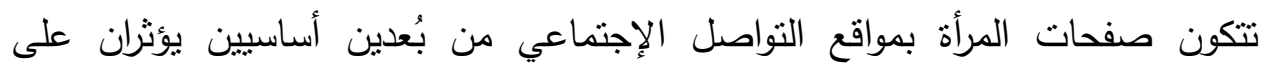

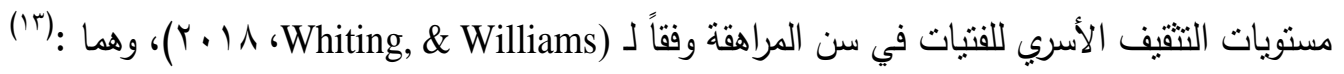
( ) بُعد رقمي: يتمثل في الأدوات التكنولوجية الرقمية التي يتضمنها استخدام صفحات التواصل الإجتماعي بالإضافة إلى كثافة الاعتماد على استخدام الوسائط المتعددة.

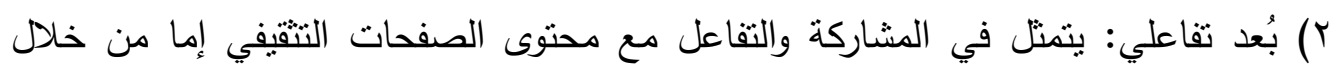

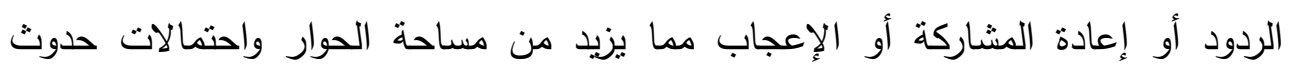

$$
\text { التثقيف الأسري. }
$$

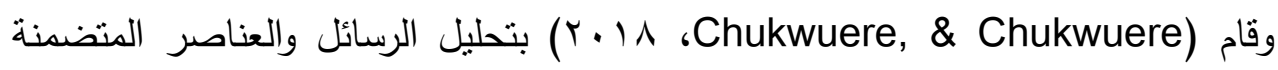

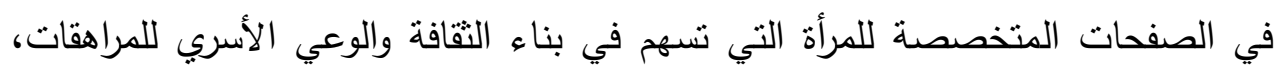
حيث توصل إلى أن هناك ما يزيد على .0\% من محتوى الصفحات يهنم بتقديم

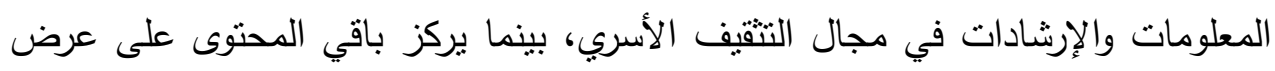

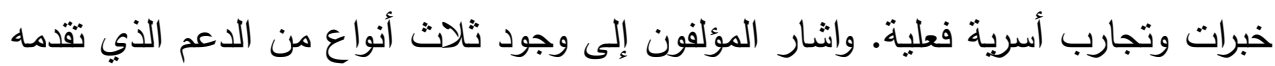

تلك الصفحات في مجال التقفيف الأسري، وهي :(1)

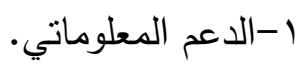
r-الدعم النفسي والعاطفي.

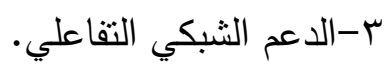


وتؤثر صفحات المرأة بمواقع التواصل الإجتماعي فيسبوك على التقيف الأسري بين

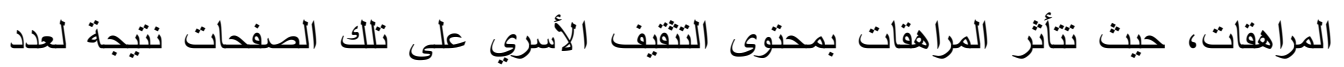

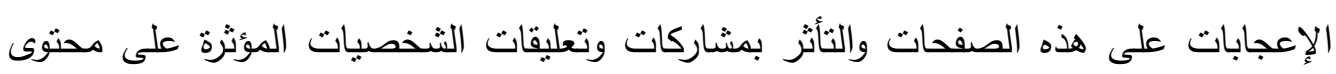

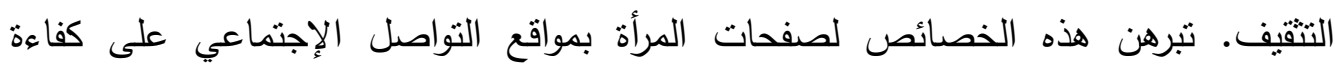

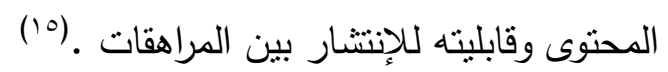
حدود الاراسة: تتمنل حدود الدراسة فيما يلي: حدود الدراسة

$$
\text { تتقسم حدود هذه الدراسة إلى: }
$$

- الحدود الموضوعية: تتمنل فى تعرض المراهقات للصفحات المتخصصة للمراة عبر مواقع

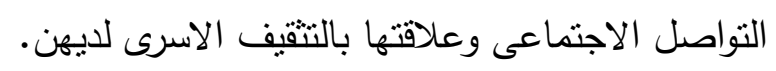
- الحدود المكانية : تتحصر في فترة تطبيق الدراسة على العينة الميدانية من المراهقات

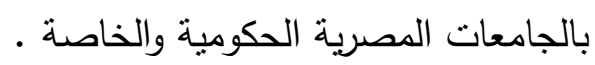

- الحدود الزمنية : تتحصر في الفترة الزمنية التي طبقت فيها الباحثة الدراسة خلال شهر

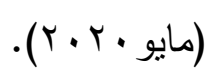

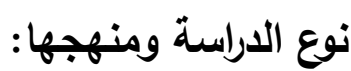

تعد هذة الدراسة من البحوث الوصفية التى تستهدف تصوير وتحليل وتقويم خصائص مجموعة معينة أو موقف معين يغلب علية صفة التحديد أو دراسة الحقائق الراهنة المتعلقة بطبيعة ظاهرة أو موقف أو مجموعة من الأحداث وذللك بهدف الحصول علي معلومات كافية

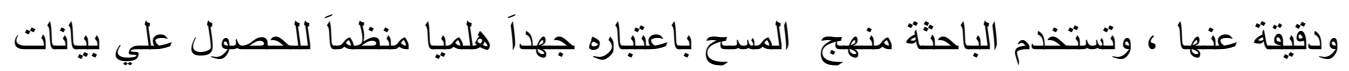
ومعلومات وأوصاف الظاهرة والأساليب التى أتبعت لمواجهة هذة الظاهرة ومعرفة كافة جوانبها المختلفة.

\section{تحديا مجتمع وعينة الدراسة:}

يتمثل المجتمع البشرى لهذه الدراسة فى المراهقات بالمرحلة الجامعية، وطبقت الدراسة

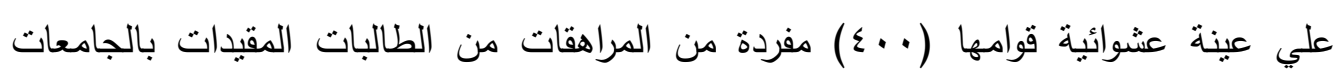
التالية (عين شمس، 7 أكتوبر ، المنوفية). 


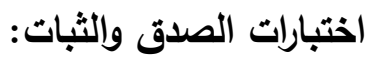

\section{صحيفة الأستقصاء:}

أعدت الباحثة صحيفة الاستبيان كاسلوب لجمع البيانات من عينة الدراسة للوقوف على

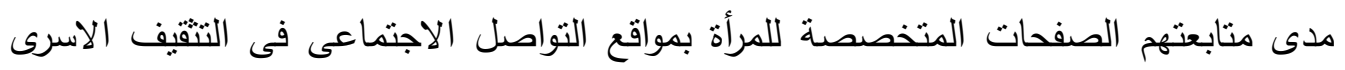
لايهن، وتم تطبيقها على عينة من المراهقات بالجامعات الحكومية والخاصة، وقد مر أعداد هذه الأدوات بالمراحل العلمية المتعارف عليها من تحديد الهدف والبيانات المطلوب جمعها وإعدادها في صورتها الأوليه، ومراجعتها منهجياً وعلمياً من خلال مجموعة من الخبراء والمحكمين في بلدي مجالات الإعلام وعلم النفس. صدق وثبات الأدوات

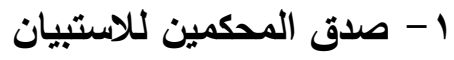

تم عرض الاستيان علي مجموعة من المحكمين المتخصصين في الإعلام في الجامعات المصرية ، وذلك بغرض دراسة مفردات الاستنيان فى ضوء التعريف الإجرائي له، وكذللك الإني

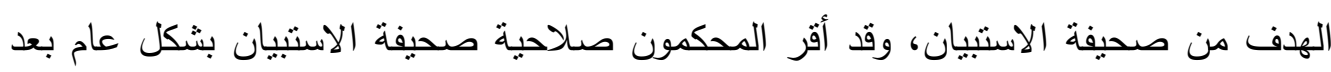

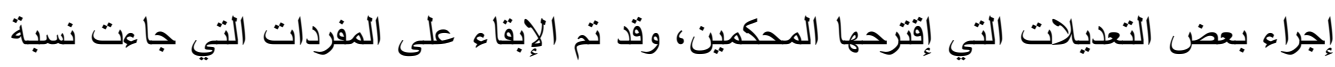
اتفاق المحكمين عليها و% فأكثر، وتم حذف بعض العبارات وتعديل بعضها في ضوء الملاحظات التي أبداها المحكمين.

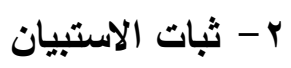

تم تطبيق الاستبيان على عينة مكونة من •ـ مفردة ثم أعيد تطبيقه مرة أخرى على المجموعة

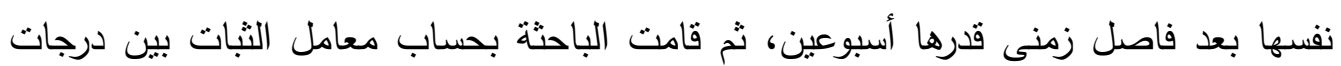
المراهقات فى التطبيقين الأول والثانى، وقد أثنارت معاملات الارتباط إلي الاتفاق بين الإجابات

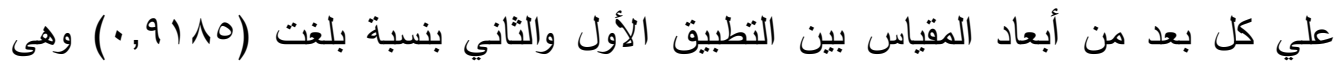

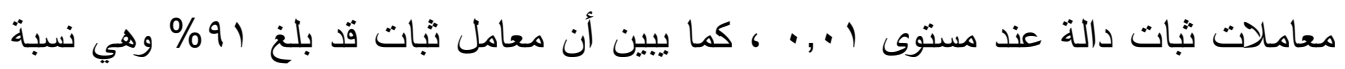
توحي بالثقة في صلاحية الاستبيان كأداة من أدوات الدراسة. 
( ) مدى متابعة المراهقات للصفحات المتخصصة للمرأة التى تقدم على مواقع التواصل الإجتماعى متابعه

\author{
جدول(1)
}

يوضح ددى متابعة المراهقات للصفحات المتخصصة للمرأة التى تقدم على مواقع التواصل الإجتماعى وفقاً للجامعة

\begin{tabular}{|c|c|c|c|c|c|c|c|c|}
\hline \multicolumn{2}{|c|}{ الإجمالي } & \multicolumn{2}{|c|}{ المنوفية } & \multicolumn{2}{|c|}{ ד أكتوبر } & \multicolumn{2}{|c|}{ عين شمس } & \multirow{2}{*}{ 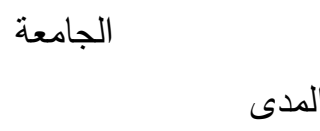 } \\
\hline$\%$ & ك & $\%$ & ك & $\%$ & ك & $\%$ & ك & \\
\hline$r \cdot, 0$ & ITY & $\curlywedge \wedge$, & Y $\varepsilon$ & $r \cdot, \Lambda$ & $\varepsilon 1$ & $\leqslant r, 0$ & ov & دائما \\
\hline $0 \wedge, \wedge$ & Tro & $\uparrow \wedge, \varepsilon$ & 91 & ov, 9 & VV & $0 ., \cdot$ & TV & أحيانا \\
\hline $1 \cdot, 1$ & $\varepsilon r$ & $1 r, 0$ & 11 & $11, r$ & 10 & $V, 0$ & 1. & y \\
\hline $1 \ldots$ & $\varepsilon \ldots$ & $1 \ldots$ & Tr & $1 \ldots$ & Irt & $1 \ldots$ & $1 \pi \varepsilon$ & الإجمالي \\
\hline دالة & 11 & & & التوا & مع & $\varepsilon=$ & -رج & قيمة كا'=r =7 ب, 19 \\
\hline
\end{tabular}

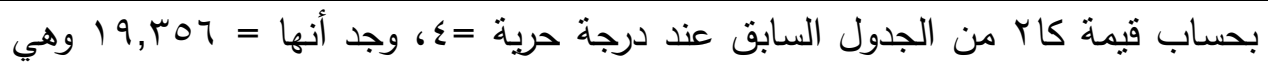

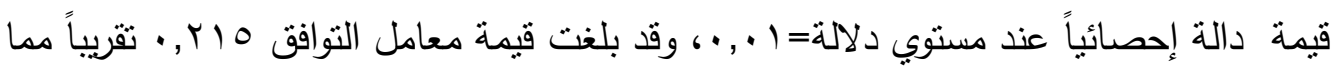

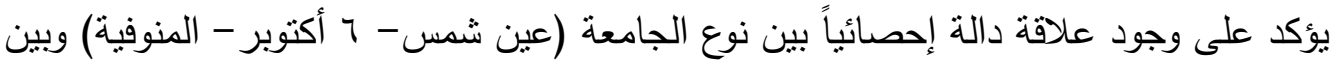

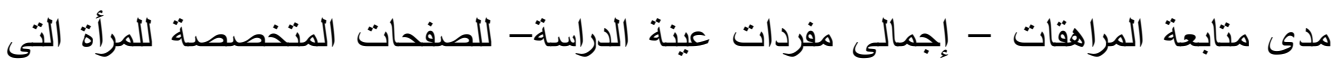
تقدم على مواقع التواصل الاجتماعي.

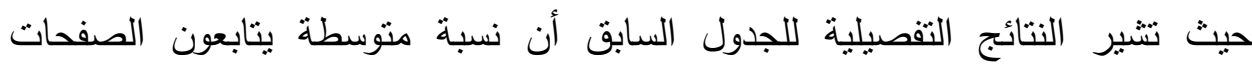

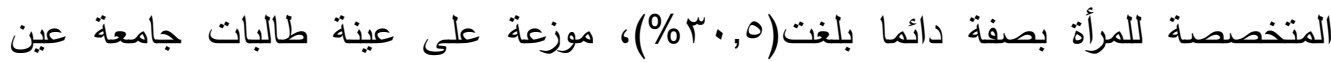

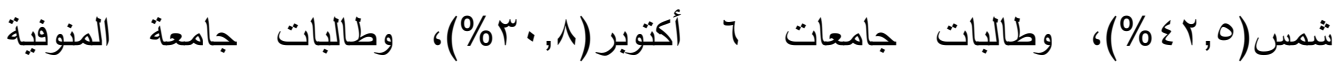

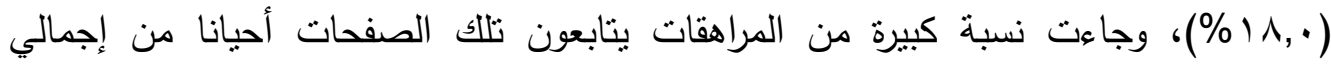

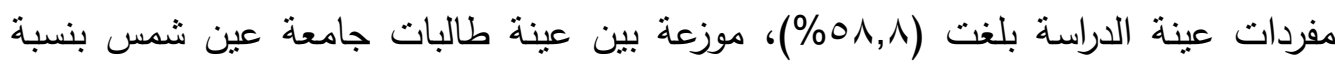

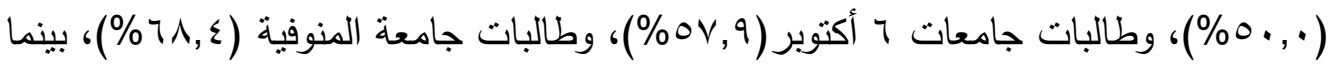

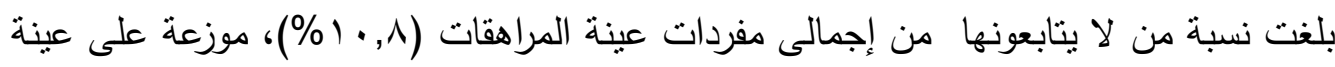

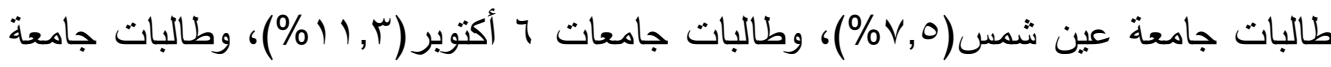

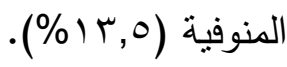


r) مدى ثقة المراهقات فيما تقدمه الصفحات المتخصصة للمراة علي مواقع التواصل الاجتماعى مدى

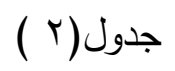

يوضح مدى ثقة المراهقات فيما تقدمه الصفحات المتخصصة للمرأة على مواقع التواصل الإجتماعى وفقاً للجامعة

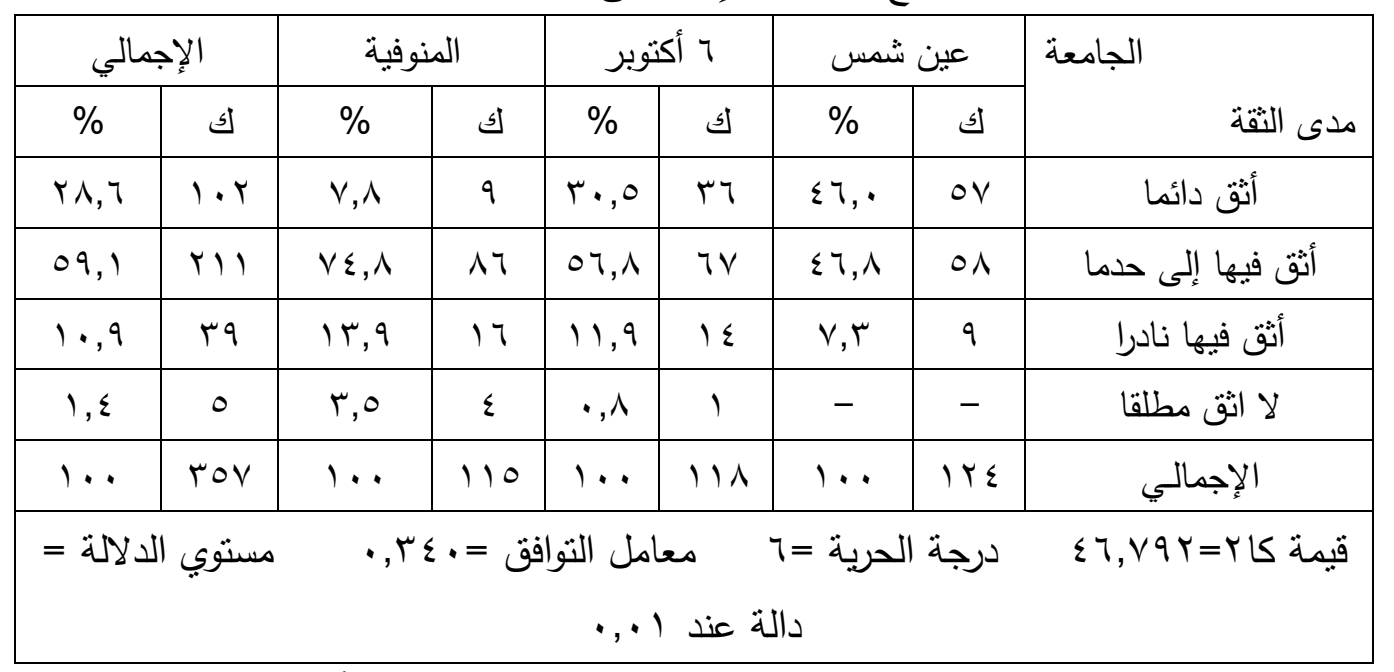

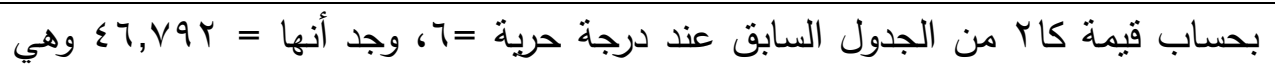

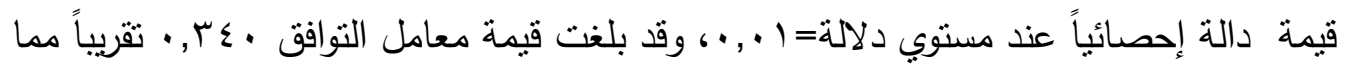
يؤكد على وجود علاقة دالة إحصائياً بين نوع الجامعة (عين شمس - 1 أكتوبر - المنوفية) وبين

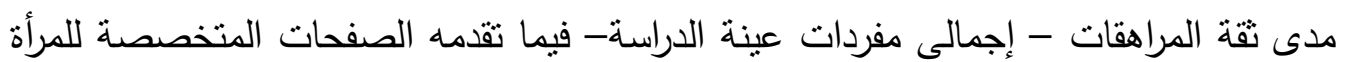
على مواقع التواصل الاجتماعي. حيث تثير النتائج التفصيلية للجدول السابق أن نسبة من يثقون دائما فيما تقدمه صفحات

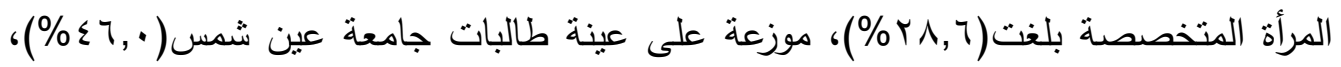

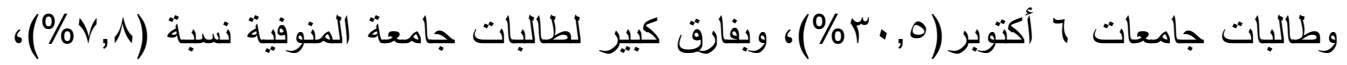
وجاءت نسبة من يثقون إلى حدما في تللك الصفحات من إجمالي مفردات عينة الدراسة بلغت

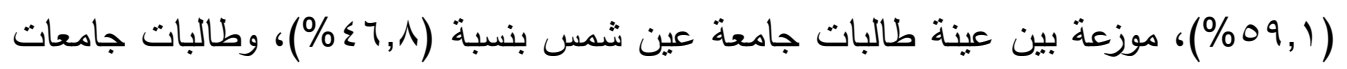

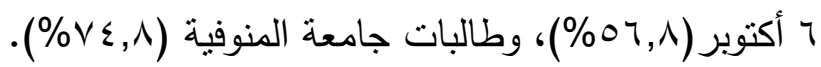

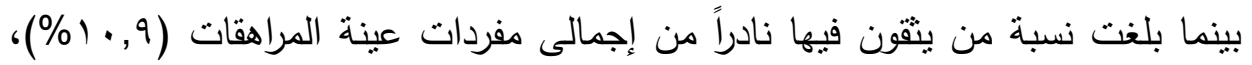

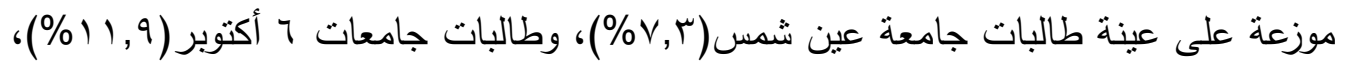

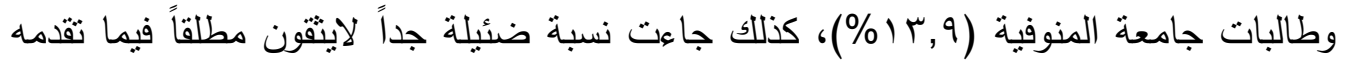

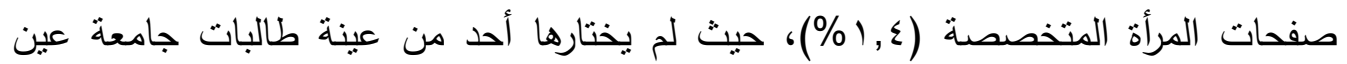


شمس، أما طالبات جامعة 7 أكتوبر فجاءت نسبتهم(^, •٪\%)، وأيضاً جاءت نسبة طالبات

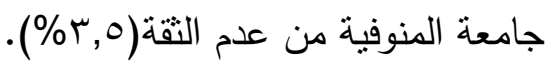
r) درجة إسهام الصفحات المتخصصة للمرأة علي مواقع التواصل الاجتماعى في التثقيف

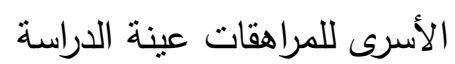

\section{جدول(r)}

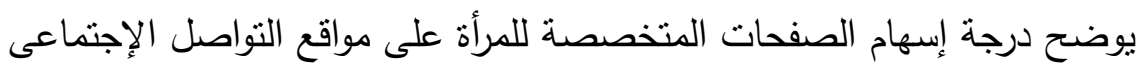

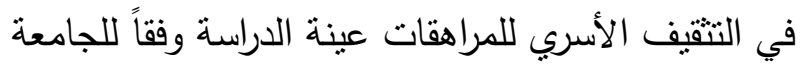

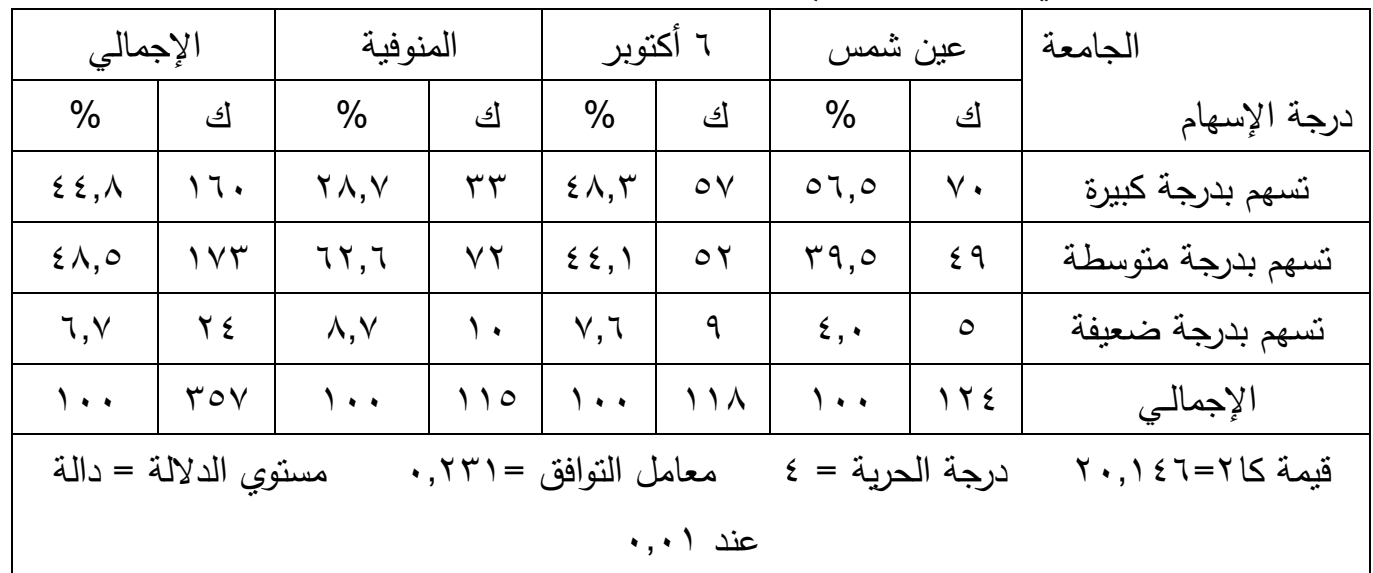

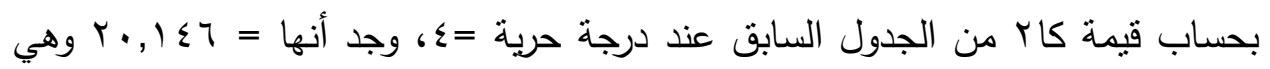

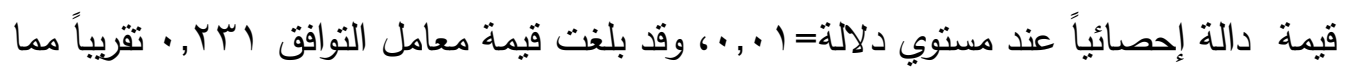

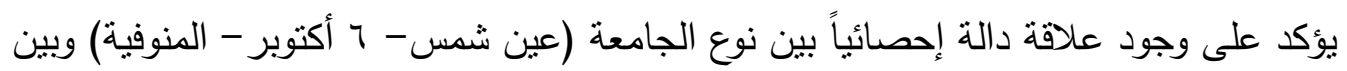

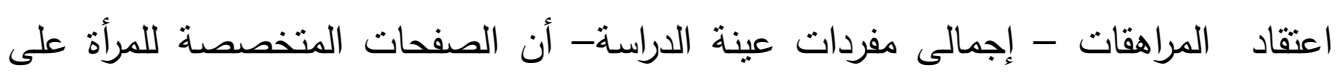
مواقع التواصل الاجتماعي تسهم في التثقيف الأسري لايهن. حيث نتير النتائج التفصيلية للجدول السابق أن نسبة من متفاوتة يرون أن الصفحات لأنيات

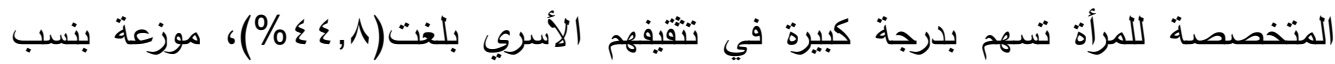

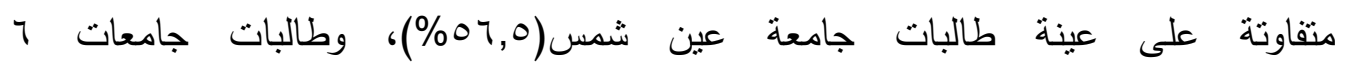

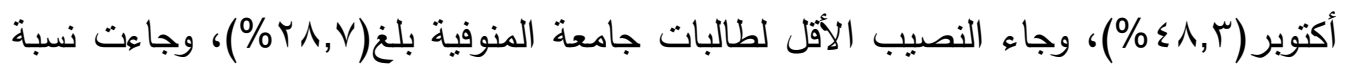
من يرون أنها تسهم بدرجة منوسطة في تثقيفهم الأسري من إجمالي مفردات عينة الدراسة بلغت

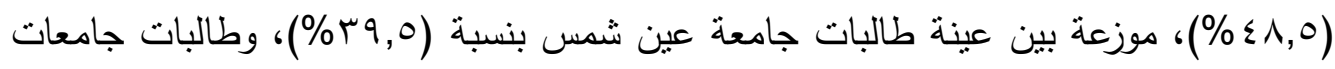

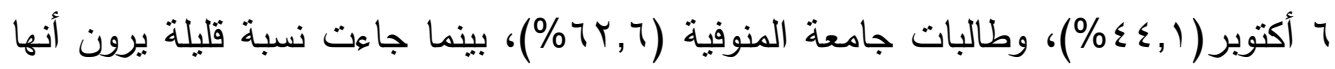

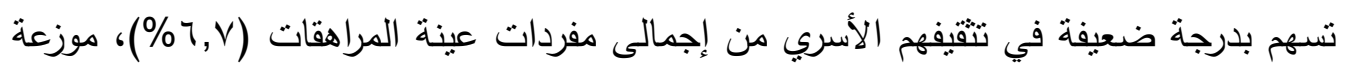




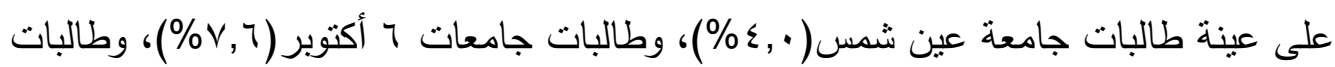

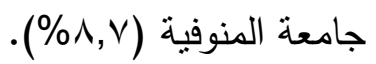

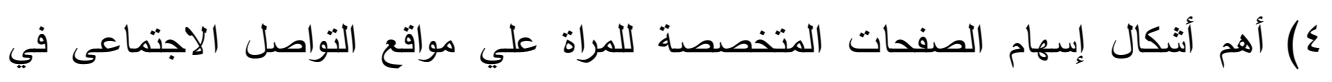
التثقيف الأسرى للمراهقات عينة الدراسة.

جدول رقم (ع)

أهم أثنكال إسهام الصفحات المتخصصة للمراة علي مواقع التواصل الاجتماعى (ألى

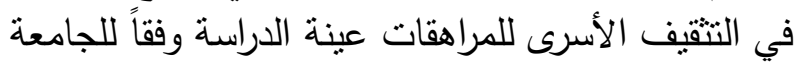

\begin{tabular}{|c|c|c|c|c|c|c|c|c|c|c|}
\hline \multirow[b]{2}{*}{ الدلالة } & \multirow{2}{*}{$\begin{array}{c}\text { قيمة كاץ } \\
\text { (k) }\end{array}$} & \multicolumn{2}{|c|}{ الإجمالي } & \multicolumn{2}{|c|}{ المنوفية } & \multicolumn{2}{|c|}{ ד أكتوبر } & \multicolumn{2}{|c|}{ عين شمس } & \multirow[b]{2}{*}{ الأشكال الجامعة } \\
\hline & & $\%$ & ك5 & $\%$ & ك & $\%$ & ك & $\%$ & 5 & \\
\hline غالة & $\cdot, \vee \backslash \leqslant$ & $\varepsilon \wedge, 0$ & iv & $\begin{array}{c}01, \\
r\end{array}$ & $\begin{array}{l}0 \\
9\end{array}$ & $\begin{array}{c}\varepsilon 0 \\
1\end{array}$ & $\begin{array}{l}0 \\
\varepsilon\end{array}$ & $\begin{array}{l}\varepsilon \wedge, \\
\varepsilon\end{array}$ & 7 & جعلتي أتعرف علي \\
\hline غير & •,rqr & $\varepsilon r, v$ & $\begin{array}{l}10 \\
7\end{array}$ & $\begin{array}{l}\varepsilon 1 \\
V\end{array}$ & $\varepsilon$ & $\begin{array}{c}\varepsilon \varepsilon, \\
1\end{array}$ & $\begin{array}{l}0 \\
r\end{array}$ & $\begin{array}{c}\varepsilon, \\
r\end{array}$ & $\begin{array}{l}0 \\
7\end{array}$ & 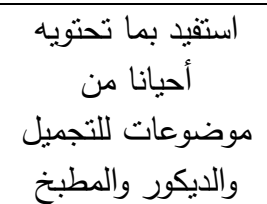 \\
\hline غير & $\cdot, \cdot 1$. & $\varepsilon 1, r$ & $\begin{array}{l}1 \leq \\
V\end{array}$ & $\begin{array}{c}\varepsilon \cdot \\
q\end{array}$ & $\begin{array}{l}\varepsilon \\
V\end{array}$ & $\begin{array}{c}\varepsilon 1, \\
0\end{array}$ & $\varepsilon$ & $\begin{array}{c}\varepsilon 1 \\
1\end{array}$ & $\begin{array}{l}0 \\
1\end{array}$ & التعرف علي تجارب \\
\hline 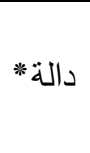 & $\vee, Y \wedge q$ & $r_{0,7}$ & $\begin{array}{l}\text { ir } \\
V\end{array}$ & $\leqslant 0$ & $\begin{array}{l}0 \\
r\end{array}$ & $\begin{array}{c}\text { r, } \\
1\end{array}$ & $\begin{array}{l}r \\
q\end{array}$ & rq, & $\begin{array}{l}r \\
y\end{array}$ & كيفية التصرف في \\
\hline غالة & Y, $Y q q$ & Tr,l & $\begin{array}{l}11 \\
1\end{array}$ & $\begin{array}{c}r \\
r\end{array}$ & $\begin{array}{l}r \\
v\end{array}$ & ro, & $\begin{array}{l}\varepsilon \\
r\end{array}$ & $\begin{array}{l}\text { Tl, } \\
0\end{array}$ & $\begin{array}{l}r \\
q\end{array}$ & وأتعايش من خلاتل \\
\hline غير & $\cdot, V \cdot T$ & $r q, \varepsilon$ & $1 \cdot$ & $\begin{array}{l}\text { YA, } \\
V\end{array}$ & r & $\begin{array}{c}\text { rr, } \\
r\end{array}$ & $\mu$ & $\begin{array}{l}r V \\
\varepsilon\end{array}$ & 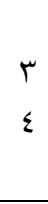 & الرجل والمراة في مالة الزواج والحياة \\
\hline غير & 1,109 & $17, r$ & 01 & $\begin{array}{c}19 \\
1\end{array}$ & $\begin{array}{l}r \\
r\end{array}$ & $\begin{array}{c}17 \\
9\end{array}$ & $\begin{array}{r}r \\
\text {. }\end{array}$ & $\begin{array}{c}\text { Ir } \\
q\end{array}$ & $\begin{array}{l}1 \\
7\end{array}$ & تخها بوستات ثقافية \\
\hline \multicolumn{4}{|c|}{ rov } & \multicolumn{2}{|c|}{110} & \multicolumn{2}{|c|}{111} & \multicolumn{2}{|c|}{ TrE } & جملة من سئلوا \\
\hline
\end{tabular}


ويتضح من تحليل بيانات الجدول السابق إلى أن " جعلتني أتعرف علي بعض ملامح وصفات الطرف الآخر " جاءت في مقدمة أنثكال إسهام الصفحات المتخصصة للمراة علي

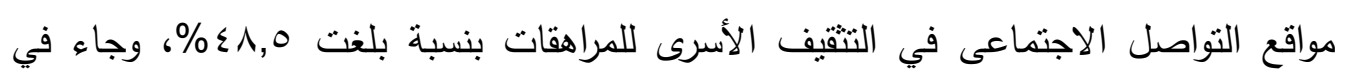
الترتيب الثاني "استقيد بما تحتويه أحيانا من موضوعات للتجميل والديكور والمطبخ " بنسبة

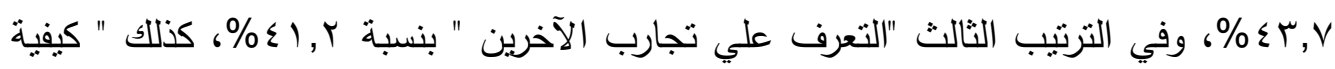
التصرف في بعض المواقف الاسرية " وذلك بالترتيب الرابع بنسبة ؟,0٪\%، تلها " أتعايش من خلال تلك الصفحات مع مشكلات أقراني وأتعلم منها التأني في إقامة علاقة مع الآخرين " بالترتيب الخامس بنسبة مئوية بلغت ربr, أمبا بالترتيب السادس فجاء إسهامها في" اعرف

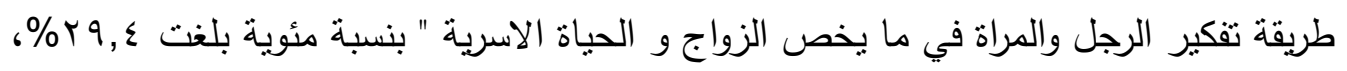
وفي التزتيب السابع والأخير جاء أنها " بها بوستات ثقافية تخص العلاقات الاسرية " بنسبة ب, 17\%. وقد أوضح النتائج التفيلية وجود فروق دالة إحصائياً في استجابات المراهقات حول أثكال إسهام الصفحات المتخصصة للمرأة بمواقع التواصل الاجتماعي في التثقف الأسري وذلك تبعاً للجامعة على النحو التالي: - فقد جاء رأي طالبات جامعات المنوفية موافقتهم بنسبة أكبر في إسهامها " كيفية التصرف في بعض المواقف الاسرية " من طالبات جامعة 7

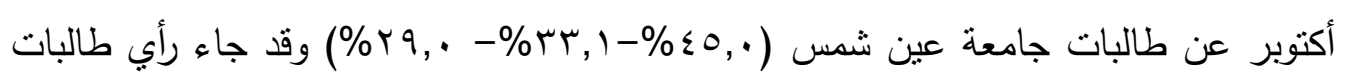
جامعة 7 أكتوبر أكثر من طالبات جامعة عين شمس والفارق دال إحصائياً حيث بلغت قيمة (k) المحسوبة V, Y و وهي أعلى من القيمة الجدولية المنبئة بوجود علاقة فارقة بين النسبتين بمستوى ثقة 90\% الفرض الأول: نوجد فروق ذات دلالة إحصائية بين جامعة(عين شمس- 7 أكتوبر - المنوفية) التى ينتمي إليها المراهقات وبين أبعاد مقياس دور الصفحات المتخصصة في زيادة التثقيف

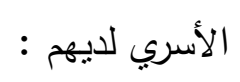




\section{جدول رقم(0)}

تحليل التباين أحادي الاتجاه (On-WayAnova) بين منوسطات درجات المراهقات على أبعاد

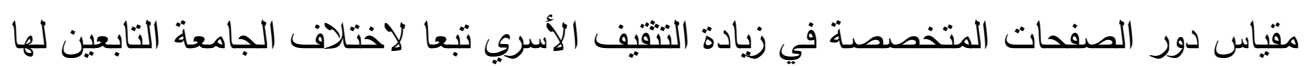

\begin{tabular}{|c|c|c|c|c|c|c|}
\hline الدلالة الد & قيمة ف & متوسط & درجة & المربعوعات & مصدر التباين & ابعاد المقباس \\
\hline \multirow{3}{*}{ دالة عند } & \multirow{3}{*}{$r, 0 \ldots$} & $\cdot, 7 \cdot 1$ & r & $1, Y 17$ & بين المجموعات & \multirow{3}{*}{ التزين وشئون } \\
\hline & & $\cdot, r \leq r$ & Tos & 17,111 & داخل المجموعات & \\
\hline & & - & rot & 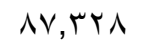 & المجموع & \\
\hline \multirow{3}{*}{ دالة عند } & \multirow{3}{*}{$r, 109$} & $\cdot, \wedge \neg r$ & r & $1, V Y \varepsilon$ & بين المجموعات & \multirow{3}{*}{ تحديد الأدوار } \\
\hline & & •, rV & ros & $97,0 \wedge \leqslant$ & داخل المجموعات & \\
\hline & & - & rot & $q \wedge, r \cdot \wedge$ & المجمـوع & \\
\hline \multirow{3}{*}{ دالة عند } & \multirow{3}{*}{ r,ovr } & $\cdot, 9 \cdot v$ & r & $1, \wedge 10$ & بين المجموعات & \multirow{3}{*}{ الأمان الأسري } \\
\hline & & $\cdot, r \circ \leqslant$ & ros & $\wedge 9,9.0$ & داخل المجموعات & \\
\hline & & - & rot & $q 1, \vee r$. & المجمـوع & \\
\hline \multirow{3}{*}{ غير } & \multirow{3}{*}{$1, \wedge 7$. } & $\bullet, \varepsilon \vee r$ & r & $\cdot, 9 \leq 0$ & بين المجموعات & \multirow{3}{*}{ والحقوق } \\
\hline & & $\cdot, r \circ \leqslant$ & Tos & $\wedge 9,91 Y$ & داخل المجموعات & \\
\hline & & - & rot & $9 \cdot, \wedge \circ V$ & المجمـوع & \\
\hline \multirow{3}{*}{ دالة عند } & \multirow{3}{*}{$r, \vee \neg \varepsilon$} & $\cdot, 7 \cdot r$ & r & $1, r \cdot \varepsilon$ & بين المجموعات & \multirow{3}{*}{ العلاقات الأسرية } \\
\hline & & $\cdot, Y \wedge$ & ros & $V V, 1 \cdot \varepsilon$ & داخل المجموعات & \\
\hline & & - & rot & $\vee \wedge, r \cdot \wedge$ & المجموع & \\
\hline \multirow{3}{*}{ دالة عند } & \multirow{3}{*}{ r, r } & $\cdot, 77 \varepsilon$ & r & I & بين المجموعات & \multirow{3}{*}{ التضحية الأسرية } \\
\hline & & $r, Y \circ \varepsilon$ & ros & $19,9.0$ & داخل المجموعات & \\
\hline & & - & rot & Q1, & المجموع & \\
\hline \multirow{3}{*}{ غبر } & \multirow{3}{*}{$r, 99$} & • & r & $\cdot, \backslash Y \wedge$ & بين المجموعات & \multirow{3}{*}{ مسئولية الأبناء } \\
\hline & & •, IV & ros & $71, r \leq 0$ & داخل المجموعات & \\
\hline & & - & rot & Tr, $\cdot V T$ & المجموع & \\
\hline \multirow{3}{*}{ دالة عند } & \multirow{3}{*}{$r, q \wedge \vee$} & 1,109 & r & q & بين المجموعات & \multirow{3}{*}{ إجمالي المقياس } \\
\hline & & $\cdot, r q 1$ & ros & l. r,qr. & داخل المجموعات & \\
\hline & & - & rot & $1 \cdot 0, r \leqslant q$ & المجمـوع & \\
\hline
\end{tabular}


تشير بيانات الجدول السابق إلي أنه توجد فروق ذات دلالة إحصائياً بين منوسطات

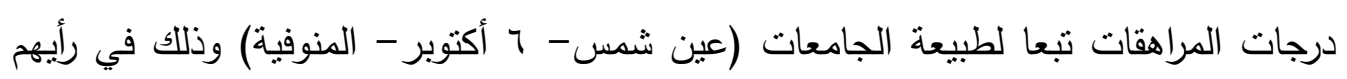
حول دور الصفحات المتخصصة بالمواقع الاجتماعية بزيادة تثقفهم الأسري في التزين وشئون

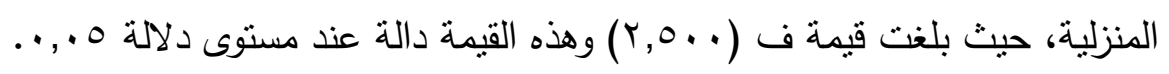

كما تثير بيانات الجدول السابق إلي أنه توجد فروق ذات دلالة إحصائياً بين متوسطات

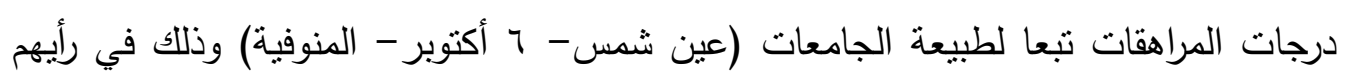
حول دور الصفحات المتخصصة بالمواقع الاجتماعية بزيادة تثقفهم الأسري في تحديد أدوارهم

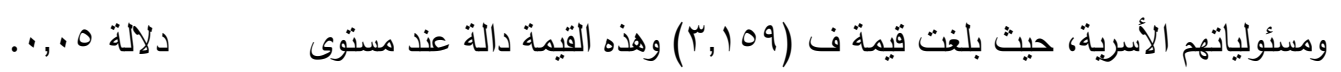
في حين تشير بيانات الجدول السابق إلي أنه توجد فروق ذات دلالة إحصائياً بين

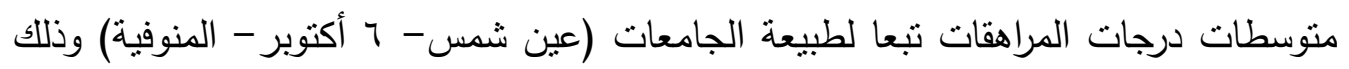
في رأيهم حول دور الصفحات المتخصصة بالمواقع الاجتماعية وفي جانب الأمان الأسري،

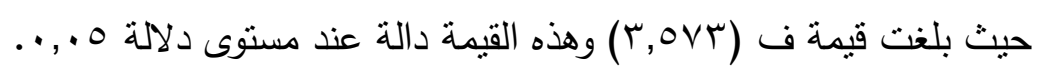

كذلك لا توجد فروق ذات دلالة إحصائياً بين متوسطات درجات المراهقات تبعا لطبيعة

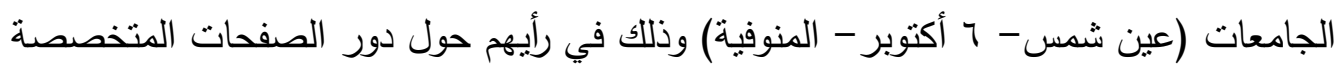

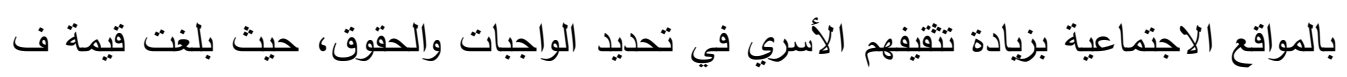

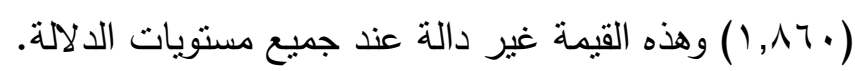

بينما تثير بيانات الجدول السابق إلي أنه توجد فروق ذات دلالة إحصائياً بين متوسطات

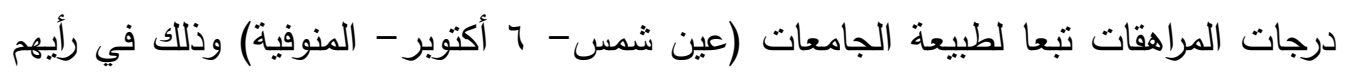
حول دور الصفحات المتخصصة بالمواقع الاجتماعية بزيادة تثقفهم الأسري في العلاقات

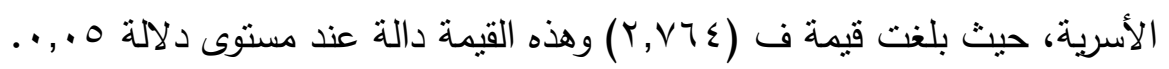

أما بيانات الجدول السابق فتتبر إلي أنه توجد فروف ذات دلالة إحصائياً بين

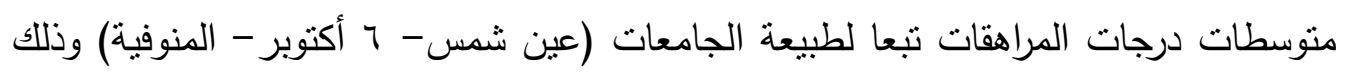

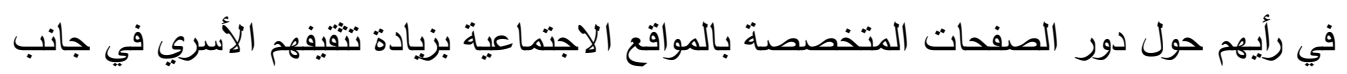

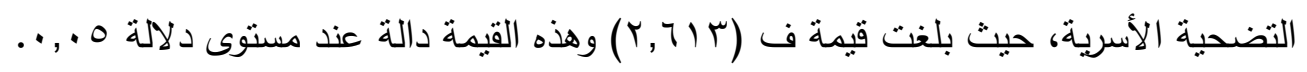


كذلك لا توجد فروق ذات دلالة إحصائياً بين متوسطات درجات المراهقات تبعا لطبيعة

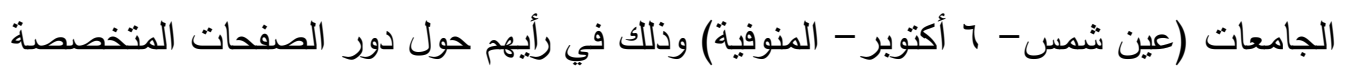

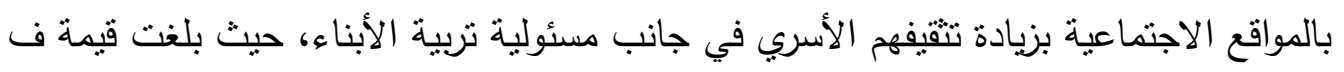

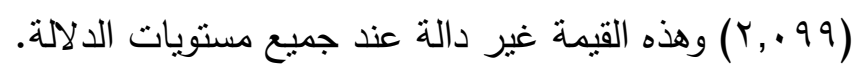

وتتير بيانات الجدول السابق إلي أنه توجد فروق ذات دلالة إحصائياً بين منوسطات درجات المراهقات تبعا لطبيعة الجامعات (عين شمس- 1 أكتوبر - المنوفية) وذلك في رأيهم حول دور الصفحات المتخصصة بالمواقع الاجتماعية بزيادة تثقيفهم الأسري على إجمالي أبعاد

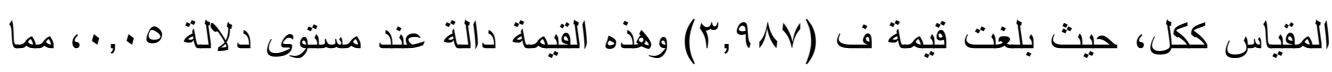

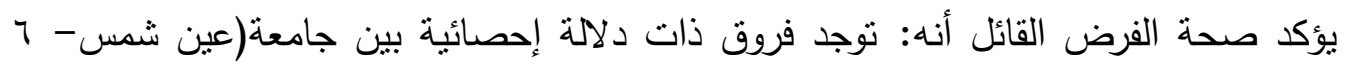

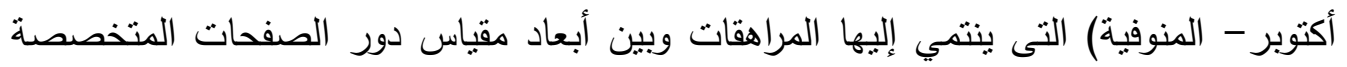
في زيادة التنقيف الأسري لديهم. فيما عدا جانب الحقوق والواجبات- مسئولية الأبناء. ولمعرفة مصدر ودلالة الفروق بين المتوسطات الحسابية لمجموعات المراهقات، تم استخدام الاختبار البعدي بطريقة أقل فرق معنوي.

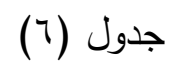

نتائج تحليل L.S.D لمعرفة الفروق بين المجموعات لرأي المراهقات تبعا لاختلاف الجامعات

\begin{tabular}{|c|c|c|c|}
\hline \multicolumn{3}{|c|}{ الجامعات } & \multirow{2}{*}{ المجموعات } \\
\hline المنوفية & 1 أكتوبر & عين شمس & \\
\hline$\cdot, \mid \vee V^{*}$ & $\cdot, \cdot 1 \mathrm{~V}$ & - & عين شمس \\
\hline$\cdot, 17 . *$ & - & $\cdot, \cdot 1 V$ & ج أكتوبر \\
\hline- &., $17 . *$ & $\cdot, \mid \vee V^{*}$ & المنوفية \\
\hline
\end{tabular}

يتبين من الجدول السابق اختلاف المتوسطات الحسابية للمجموعات الذين يمثلون متوسطات درجات المراهقات تبعا لطبيعة الجامعة "عين شمس- 7 أكتوبر - المنوفية" ومتوسطات درجاتهم على مقياس دور الصفحات المتخصصة في التتقيف الأسري للمراهقات، ولمعرفة مصدر ودلالة الفروق بين المتوسطات الحسابية لمجموعات المبحوثين، نم استخدام الاختبار البعدي بطريقة أقل فرق معنوي. 
حيث اتضح أن هنالك اختلافًا بين طالبات جامعة عين شمس ومتوسطات درجات طالبات

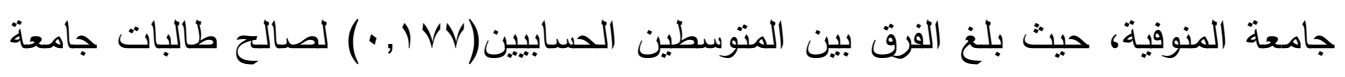
عين شمس، وهو فرق دال إحصائيا عند مستوى دلالة ه.,.،، كما ظهر أنه هناك اختلافنًا بين متوسطات درجات طالبات جامعة 7 أكتوبر وبين منوسطات درجات طالبات جامعة المنوفية،

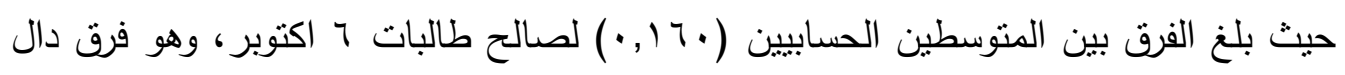
إحصائيا عند مسنوى دلالة 0 .,. ..

الفرض الثاني: توجد علاقة ارتباطية إيجابية بين تعرض المراهقات لصفحات المرأة المتخصصة بمواقع التواصل الاجتماعي وبين زيادة التقيف الأسري لايهم.

$$
\text { جدول رقم (v) }
$$

معامل ارتباط سبيرمان Spearman بين تعرض المرهقات لصفحات المرأة المتخصصة بمواقع

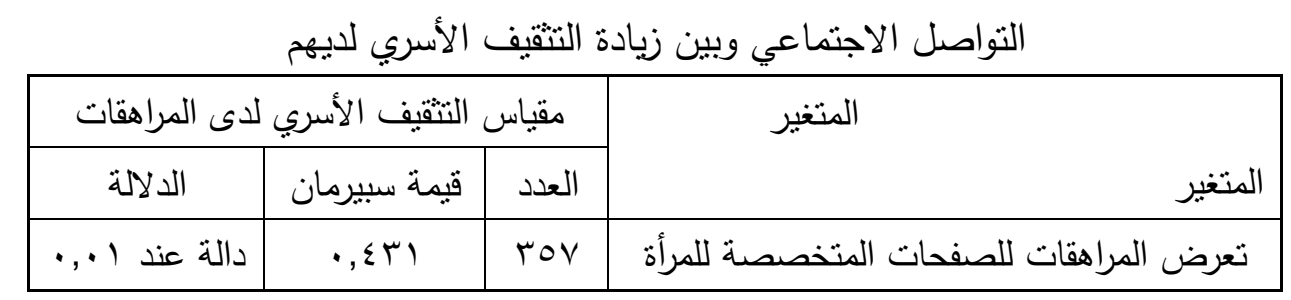

تتير نتائج الجدول السابق أنه باستخدام معامل ارتباط سبيرمان أتضح وجود علاقة لإنة ارتباطيه موجبة طرديا ودالة إحصائياً بين زيادة التثقيف الأسري للمراهقات عينة الدراسة وبئ وبين

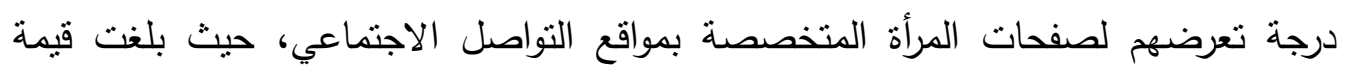

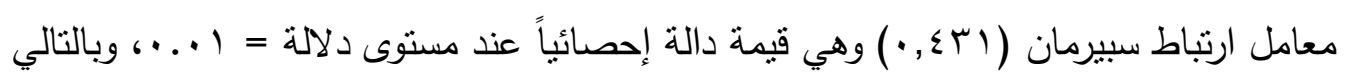

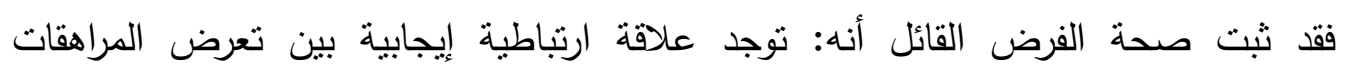

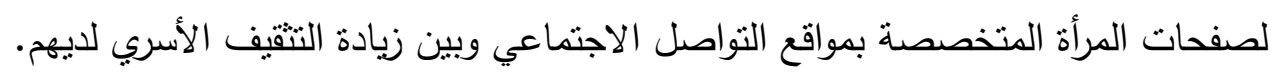




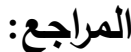

1- Brandes, S. B., \& Levin, D. (Y.Y•). "Only for Girls": Teenage Girls Usage of Facebook Social Network Pages and Connection to Family Culture, Feminist Media Studies; $1 \cdot(r)$.

r- Clary, P. C.; Markham, M. S., \& Myers-Bowman, K. S. (Y.r•). Effects Of Social Networking Sites Pages On Family Life Educations Of Adolescent Females, Journal of Technology in Human Services; Social Work in Health Care, or (9).

r- Pi, S.; Chou, C., \& Liao, H. (ץ.19). Study Of Facebook Women's Groups Members' Knowledge Sharing On Family Life Awareness For Teen Girls, Computers in Human Behavior; $r q(1)$ ).

乏- Jong, S. T., \& Drummond, M. J. N. (Y.19). Immediate Feedback On Social Networking Sites Women's Pages And The Impact On Adolescent Girls Family Life Education, Asia-Pacific Journal of Health, Sport and Physical Education; $1 \%(\varepsilon)$.

-. Park, N.; Kee, K. F., \& Valenzuela. S. (Y.19). Being Engaged in Social Networking Environment: Facebook Women Groups, Uses and Gratifications, and Family Education Outcomes for Teen Females, Cyberpsychology \& Behavior; $1 \mathrm{r}(\mathrm{\wedge})$.

7. Sangeetha, N., \&Vanitha, J. (Y.19). A Study on the Impact of Social Media Pages in Relation to Social Familial Awareness among High School Female Students, International Journal of Education; $\vee(r)$.

V- Adhikary, R. W., Lingard, B., \& Hardy, I. (r. i ^). A critical examination of Teach for Bangladesh's Facebook page: "Social-mediatisation" of global education reforms in the "post-truth" era. Journal of Education Policy, rr( $(\bullet), p^{\top} r r$.

^- Procházka, O. $(\lceil\cdot \mid \wedge)$. A chronotopic approach to identity performance in a Facebook meme page. Discourse, Context \& Media. doi: $1 \cdot .1 \cdot 17 / j . d c m . r \cdot 1 \lambda . \cdot r . \cdot 1 \cdot, p^{r o}$.

9- Salloum, S. A.; Mhamdi, C.; Al-Emran, M., \& Shaalan, K. (Y.। V). Analysis and Classification of Arabic Newspapers' Facebook Pages using Text Mining Techniques, International Journal of Information Technology and Language Studies (IJITLS); ' ( $), \mathrm{p}^{\wedge}$.

1.- Ma, W.W., Chan, A., (Y.iv). Knowledge sharing and social media: altruism, perceived online attachment motivation, and perceived online relationship commitment. Comput. Hum. Behav. rq, 01 .

1)- Kimeto, J. $(r / 9)$. The Effect Of Social Media On Family Life Education :A Case Of Lang'ata Constituency, Nairobi County, Keny, MA Thesis, Pan Africa Christian University Nairobi, Kenya, p $^{\circ}$.

IY- Aruna, D. S.; Mavatkar, M., \& Usha, R. C. (Y.19). Effectiveness of communitybased intervention on family life education among school-going adolescent girls in a village of Andhra Pradesh, International Journal of Medical Science and Public Health Online; $\wedge$ ( 1 r), p $\uparrow \wedge$.

$1 r$ - Whiting, A., Williams, D., $(\uparrow \cdot \mid \Lambda)$. Why people use social media: a uses and gratifications approach. Qual. Mark. Res. Int. J. 1 ( ( $)$, r $r$ r.

I $\leqslant$ - Chukwuere, J. E., \&Chukwuere, P. C. $(Y \cdot \mid \wedge)$. The Impact Of Social Media Women Pages On Social Family Education: A Case Study Of University Female Students, Gender \&Behaviour; $\circ$ ( I V), $p \leqslant \vee$.

10. Mao, Y., \& Qian, Y. (Y.|^). Facebook use and acculturation: The case of overseas Chinese professionals in Western countries. International Journal of Communication, $9(r), p \leqslant \tau$. 